\title{
Is allograft aortic valve replacement still an option? When, which, where?
}

\author{
Manuel J. Antunes, MD, PhD, DSc
}

From the Center of Cardiothoracic Surgery, University Hospital and Faculty of Medicine, Coimbra, Portugal. Disclosures: Author has nothing to disclose with regard to commercial support.

Received for publication April 30, 2018; revisions received April 30, 2018; accepted for publication May 2, 2018; available ahead of print June 27, 2018.

Address for reprints: Manuel J. Antunes, MD, PhD, DSc, Centre of Cardiothoracic Surgery, Centro Hospitalar Universitário de Coimbra, Praceta Prof. Mota Pinto, 3000-075 Coimbra, Portugal (E-mail: antunes.cct. chuc@sapo.pt).

J Thorac Cardiovasc Surg 2018;156:1366-7

$0022-5223 / \$ 36.00$

Copyright (c) 2018 by The American Association for Thoracic Surgery

https://doi.org/10.1016/j.jtcvs.2018.05.011

Aortic valve disease is today generally treated by replacement with a prosthesis, mechanical or biological, and in a few cases using valve repair. Compared with the mitral valve, aortic valve prostheses have a lower incidence of serious complications, hence surgeons feel more at ease to replace rather than repair the aortic valve. However, there are subgroups of patients in whom replacement of the aortic valve still constitutes "exchanging one disease for another," such as in young patients and in women of child-bearing age, who have relative contraindications to anticoagulation therapy and in whom bioprostheses are prone to earlier biodegradation.

Allografts, fresh and cryopreserved, have in these cases an ideal field for application. They offer excellent hemodynamic performance and do not require anticoagulation. However, long-term durability is influenced by structural valve deterioration, not yet fully quantified, which requires frequent reoperation and is frequently fatal. Although the most important field for allograft use is congenital disease, in which aortic and pulmonary allografts have specific indications, use as an aortic valve substitute in acquired disease has gained increasing acceptance, especially for the treatment of aortic valve endocarditis.

In this issue of The Journal of Thoracic and Cardiovascular Surgery, Nappi and colleagues, ${ }^{1}$ from 5 institutions in France, Italy, and the United Kingdom, report on their experience with the use of cryopreserved allografts for aortic valve replacement in 210 patients who received surgery from 1993 to 2010, either using a free-hand subcoronary implantation technique $(\mathrm{n}=55)$ or as root replacement with coronary reimplantation $(\mathrm{n}=155)$. Both techniques have been reported previously as suitable and leading to similar outcomes. Approximately half of the patients had endocarditis and nearly a quarter had associated valvular or coronary procedures. The authors aimed at assessing "long-term results of aortic allografts and to identify factors influencing long-term durability." Although comparison of the 2 techniques was not their primary aim,

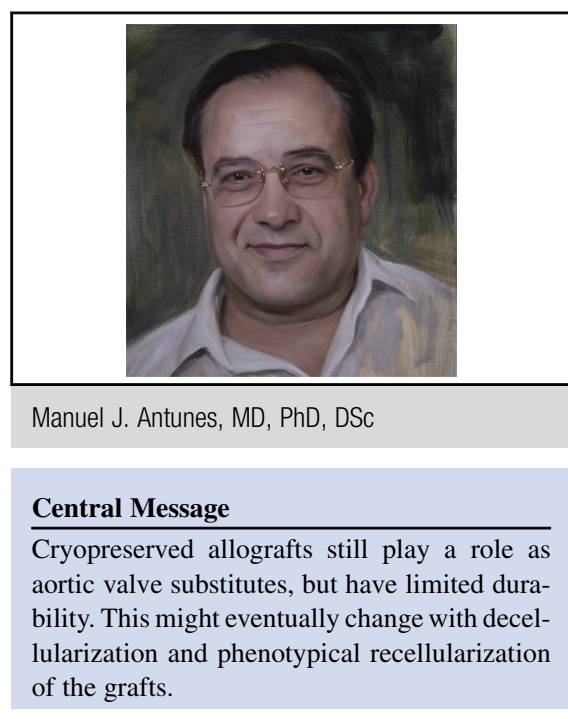

See Article page 1357.

they did attempt such comparison and, again, reported no significant differences.

After a mean follow-up of 13 years (maximum, 20 years), overall mortality and cardiac mortality occurred in $38.1 \%$ and $30.5 \%$ of patients, respectively, and structural valve disease required reoperation in $27.1 \%$ of the cases. There were no early and only 4 late instances of endocarditis.

Perhaps the most interesting aspect of this work was the fact that there were 44 women of child-bearing age of whom 37 got pregnant, some more than once, during the study period and the authors did not unveil differences in the clinical outcomes among women who became pregnant and those who did not. Also, there was no association between the number of subsequent pregnancies and the risk of allograft degeneration, which is in contrast to what has been described for bioprostheses use. The authors believe that this has not been reported previously.

The authors hence conclude that "cryopreserved allograft is a valid option especially in complex infective endocarditis and in women of child-bearing age. A careful choice of allograft size and implantation technique can reduce risk of structural valve deterioration."

The present study, like many others, fails to show a definitive advantage of aortic allograft over prosthetic valve replacement, with the exception of 3 groups of patients that, in my view, remain the principal indication for the 
use of these valve substitutes in noncongenital valve pathology: children and adolescents, women of child-bearing age, and aortic endocarditis, especially prosthetic endocarditis. In my group's experience, the use of allografts is an absolute must in the treatment of prosthetic valve endocarditis and we have not registered a single case of recurrence of the infection up to 10 years of follow-up. The 10-year survival was $79 \%{ }^{2}$

Availability remains the most important drawback of the use of allografts. Cryopreserved allografts are not at the reach of most surgical centers around the world. They are commercially available in the United States and in selected European countries, but not everywhere. Many centers developed their own allograft bank. I, like many others, use fresh allografts, preserved in a nutrient medium and antibiotic-sterilized, harvested as part of our heart transplantation program. Fresh allografts were first used with good results but preservation remains a problem. Koolbergen and colleagues reported that during the first year of implantation, homograft valves rapidly lose their cellular components and normal tissue architecture. ${ }^{3}$ In their study of 40 explanted allografts, a low-grade inflammatory response was observed, but no convincing evidence of immune-mediated injury was found.

Cryopreservation appears to significantly alter the allograft structure, which might be responsible for their inferior clinical results. New techniques of preparation and preservation of these valves are urgently needed. Decellularization and newer methods of scaffolding might eventually be the answer. However, despite early promising results, it is still too early to know whether the decellularized grafts will have greater long-term durability. Recellularization of the valve leaflets or the entire allograft by phenotypically appropriate cells appears to be the next step.

In the meantime, stentless xenografts might be a reasonable alternative. A randomized study between allografts and xenografts just presented at the American Association for Thoracic Surgery showed similar survival, and freedom from reoperation and from infective endocarditis up to 20 years, but better freedom from valve dysfunction in the xenograft (Freestyle; Medtronic Inc, Minneapolis, Minn). ${ }^{5}$ In addition, they might become a good base for tissue engineering strategies in the future. In this case, availability will not be a limitation.

\section{References}

1. Nappi F, Nenna A, Petitti T, Spadaccio C, Gambardella I, Lusini M, et al. Longterm outcome of cryopreserved allograft for aortic valve replacement. J Thorac Cardiovasc Surg. 2018;156:1357-65.

2. Lopes S, Calvinho P, Oliveira F, Antunes M. Allograft aortic root replacement in complex prosthetic endocarditis. Eur J Cardiothorac Surg. 2007;32:126-32.

3. Koolbergen DR, Hazekamp MG, de Heer E, Bruggemans EF, Huysmans HA, Dion RA, et al. The pathology of fresh and cryopreserved homograft heart valves: an analysis of forty explanted homograft valves. J Thorac Cardiovasc Surg. 2002; 124:689-97.

4. VeDepo MC, Detamore MS, Hopkins RA, Converse GL. Recellularization of decellularized heart valves: progress toward the tissue-engineered heart valve. J Tissue Eng. 2017;8:1-21.

5. Melina G, De Robertis F, Gaer JA, Angeloni E, Bahrami T, Bellazzi E, et al. Twentyyear survival following the Freestyle versus Homograft Aortic Root Replacement Prospective Randomized Trial. Presented at: 98th Annual Meeting of The American Association for Thoracic Surgery; April 29, 2018; San Diego, Calif. 